OPEN ACCESS

Edited by:

Jean-Philippe Herbeuval,

UMR8601 Laboratoire de Chimie et Biochimie Pharmacologiques et

Toxicologiques, France

Reviewed by:

Nikaïa Smith,

Institut Pasteur, France

Géraldine Schlecht-Louf,

INSERM U996 Inflammation,

Chimiokines et Immunopathologie,

France

*Correspondence:

Jean-Charles Guéry

jean-charles.guery@inserm.fr

Specialty section:

This article was submitted to

Cytokines and Soluble

Mediators in Immunity,

a section of the journal

Frontiers in Immunology

Received: 22 June 2021 Accepted: 05 August 2021

Published: 27 August 2021

Citation:

Guéry J-C (2021) Sex Differences in Primary HIV Infection: Revisiting the

Role of TLR7-Driven Type 1 IFN

Production by Plasmacytoid

Dendritic Cells in Women.

Front. Immunol. 12:729233.

doi: 10.3389/fimmu.2021.729233

\section{Sex Differences in Primary HIV Infection: Revisiting the Role of TLR7-Driven Type 1 IFN Production by Plasmacytoid Dendritic Cells in Women}

\section{Jean-Charles Guéry*}

Institut Toulousain des Maladies Infectieuses et Inflammatoires (INFINITY), Université de Toulouse, INSERM, CNRS, UPS, Toulouse, France

Plasmacytoid dendritic cells (pDCs) produce type I interferon (IFN-I) during HIV-1 infection in response to TLR7 stimulation. However, IFN-I-signaling has been shown to play opposite effects in HIV-1 and SIV infection. TLR7-driven type I interferon production in pDCs is higher in women than in men due to the cell-intrinsic actions of estrogen and $X$ chromosome complement. Indeed, TLR7 is encoded on the X-chromosome, and the TLR7 gene escapes the X-chromosome inactivation in immune cells of women which express significantly higher levels of TLR7 protein than male cells. Following HIV infection, women have a lower viremia during acute infection and exhibit stronger antiviral responses than men, which has been attributed to the increased capacity of female pDCs to produce IFN- $\alpha$ upon TLR7-stimulation. However, a deleterious functional impact of an excessive TLR7 response on acute viremia in women has been recently revealed by the analysis of the frequent rs179008 c.32A $>$ T SNP of TLR7. This SNP was identified as a sex-specific protein abundance quantitative trait locus ( $\mathrm{PQTL}$ ) causing a difference in the TLR7 protein dosage and effector function in females only. T allele expression was associated with a lower TLR7 protein synthesis, blunted production of IFN- $\alpha$ by pDCs upon TLR7 stimulation, and an unexpectedly lower viral load during primary HIV-1 infection in women. In the present review, the author will revisit the role of TLR7-driven pDC innate function in the context of HIV-1 infection to discuss at what stage of primary HIV-1 infection the TLR7 rs179008 T allele is likely to be protective in women.

Keywords: HIV, innate immunity, sex bias, type I IFN, plasmacytoid dendritic cells, Toll-like receptor 7

\footnotetext{
Abbreviations: HIV-1, human immunodeficiency virus 1; SIV, simian immunodeficiency virus; pDCs, plasmacytoid dendritic cells; TLR7,Toll-like receptor 7; IFN-I, type 1 interferon; ISG, interferon stimulated genes; ART, antiretroviral therapy; pQTL, protein expression quantitative trait locus; IFNAR, type I IFN receptor.
} 


\section{INTRODUCTION}

Sex differences in the acquisition and pathogenesis of HIV-1 disease between men and women have long been reported in epidemiological studies, reviewed in $(1,2)$. Women have half the plasma viral load men have in both acute/primary and chronic HIV-1 infection in the absence of treatment (3-5), while such difference has no influence on time to AIDS progression between sex (6). A more robust type I interferon (IFN-I) response during primary HIV infection in women relative to men has been hypothesized to explain the initial plasma viremia differences between sex (2). Assertion supported by the observation that following viral replication adjustment, women had a higher expression of IFN stimulated genes (ISG) in T cells and higher levels of $\mathrm{T}$ cell activation as compared to men $(7,8)$. The strength of the innate and adaptive immune responses of women is generally greater than those of men (9), and in part explained by the qualitative and quantitative differences in plasmacytoid dendritic cells (pDCs) innate function between sex (10). Indeed, pDCs are specialized in the production of IFN-I through TLR7 signaling and play an important role in bridging innate and adaptive immunity in the context of HIV-1 infection (11). Cell-associated and, less efficiently, cell-free HIV-1 virions signal through TLR7 to induce IFN-I and other pro-inflammatory cytokines and chemokines $(12,13)$. An elevated plasma IFN-I level characterizes the acute and late chronic phases of the infection $(14,15)$. Studies of macaques infected with simian immunodeficiency virus (SIV) point to pDCs as the critical IFN-I producers in this process (16, 17). Likewise, in humanized mice, depletion of pDCs prior to HIV-1 infection boosted HIV-1 replication and abolished serum IFN-I elevation and the expression of ISG (18). However, pDC-derived IFN-I production was also associated with the capacity of HIV-1 to induce cell death, immunosuppressive pathways, and immunopathogenesis during the acute phase of primary infection (16-18). Likewise, studies in the SIV infection model have also provided a contrasting view suggesting that the beneficial or detrimental role of pDCs and IFN-I may vary depending on the timing (19) or the site of infection (20). Indeed, in the course of intrarectal SIV infection, an initial IFN- $\alpha 2$ a administration prevented systemic infection (19), supporting a beneficial effect of IFN-I during acute infection (21). Moreover, an intravaginal infection in female macaques pointed to a deleterious role of the epithelium-innate immune cells axis, characterized by an early pDC recruitment and activation locally underneath the epithelium layer of the endocervix (20). In the chronic phase of the infection, a continued IFN- $\alpha 2 \mathrm{a}$ treatment in the course of intrarectal SIV infection accelerated $\mathrm{CD}_{4}^{+} \mathrm{T}$ cell depletion, disease progression, and death from AIDS (19), suggesting a detrimental effect of IFN-I as the disease progresses $(21,22)$.

The frequency of pDCs producing IFN- $\alpha$ is significantly higher in women than in men upon TLR7 engagement $(8,23,24)$, which correlates, during primary infection, with the clinical differences in the course of HIV-1 infection together with a greater expression of ISG $(7,8)$. It has been proposed that these sex differences in the responses to HIV-1 hinge in a large part on the sex bias in IFN-I production by pDCs (25). However, the role of TLR7-driven pDC activation and IFN-I production in HIV-1 patients is not clearly defined. Recently, we examined this question in terms of the frequent single nucleotide polymorphism (SNP) of TLR7 rs179008 c.32A>T, which was found to selectively impair the TLR7 protein expression and TLR7-driven production of IFN- $\alpha$ by pDCs in women, but not in men (26). The minor $\mathrm{T}$ allele of rs179008 is especially frequent among European populations, where $30 \%-50 \%$ of women are homozygous or heterozygous carriers, and common worldwide except in East Asia. Contrary to the expectation, we observed that the blunted interferogenesis in women who were carriers of the T-allele was associated with a lower viremia and reduced frequency of symptoms at acute HIV-1 infection when exploring the French PRIMO cohort which is composed of women infected by sexual transmission (26). Thus, we demonstrated for the first time that the TLR7 rs179008 is a sexspecific protein expression QTL (pQTL) of potential significance in the control of HIV-1 viral infection specifically in women.

In the present review, the author will revisit the role of TLR7driven $\mathrm{pDC}$ innate function in the context of HIV-1 infection to discuss at what stage of primary HIV-1 infection. Based on the recent study (26), the author will also propose that the higher propensity of female pDCs to produce IFN-I in response to TLR7 stimulation is unlikely to contribute to the sex differences in an acute HIV-1 infection.

\section{Biological Sex is an Important Driver of Toll-Like Receptor 7 Mediated Type 1 Interferon Production by Plasmacytoid Dendritic Cells}

The plasma HIV-1 RNA load at the "set point" $(4-6,27)$ as well as the associated HIV-1 DNA reservoir cells $(28,29)$ are lower in women compared to men. The most classically suggested hypothesis to explain this gender bias is the difference in the innate immunity observed between men and women (25). Indeed, the frequency of IFN- $\alpha$-producing pDCs is higher in women compared to men after the stimulation with TLR7 ligands $(8,10,24)$. One of the mechanisms explaining this enhanced activation threshold of pDCs in female is related to estrogens $(24,30)$. Interestingly, beside the female sex hormone effect, it was also shown that X-chromosome dosage contributed to this sex biased response of pDCs (31). TLR7 is encoded on the $\mathrm{X}$-chromosome, and we recently showed that the TLR7 gene escapes X-chromosome inactivation in female immune cells (32). This mechanism is responsible for a significant increase in the amount of TLR7 protein in the leukocytes of women compared to men (32), and probably contribute to the enhanced capacity of pDCs to express higher levels of TLR7 mRNA and to transcribe higher levels of IFN- $\alpha / \beta$ mRNA at a steady state and in response to TLR7 ligands (33). Thus, both estrogen-signaling and Xlinked genetic factors contribute to the stronger functional response of female pDCs $(24,30,31)$.

\section{Sex-Specific Impact of the Toll-Like Receptor 7 rs179008 Protein Expression Quantitative Trait Locus on Plasmacytoid Dendritic Cells Innate Functions}

The female predominance in the TLR7-driven production of IFN-I by pDCs represents a robust phenotype that distinguish 
the innate immunity between men and women, then it is not surprising that genetic mutations have been selected during the evolution to counterbalance this effect. Among them, the NM_016562.3:c.32A $>$ T (dbSNP rs179008) polymorphism of TLR7 is a missense SNP substituting a leucine (c.32A) for a glutamine (c.32T, p.Gln11Leu) in the leader sequence of the TLR7 protein. This SNP was previously identified by Oh and coll (34) as a risk factor for being infected by HIV-1 in c.32T allele carriers in women but not in men, whereas an accelerated deterioration of $\mathrm{CD}^{+}{ }^{+} \mathrm{T}$-cell counts was also reported in men carrying the T0 (c.32T) genotype (Figure 1) (34). Not tested in women by $\mathrm{Oh}$ and coll (34), the functional impact of rs179008 c.32T on protein expression and in TLR7-driven $\mathrm{pDC}$ responses was recently examined in both sexes (26). Interestingly, the stronger TLR7-driven IFN- $\alpha$ responses of $\mathrm{pDCs}$ from women as compared to men $(8,23,24)$ was further magnified when all carriers of the c.32T allele of TLR7 were excluded from the analysis (26). Mechanistically, c.32 T allele was identified as a sex-specific pQTL found to determine the lower TLR7 protein expression in female leukocytes, which mirrored its negative functional impact on the TLR7-driven production of IFN- $\alpha$ by pDCs from women but not from men (Figure 1). Unusually, this nonsynonymous SNP affects the signal peptide which controls protein dosage at the translational level through the mRNA sequence itself, rather than through the alteration of the signal peptide function. Indeed, evidence was provided for a translation rate-limiting role of $\mathrm{Leu}_{11}$ codon in allele T leader peptide. Leu1 1 corresponds to the first rare codon in the path of the ribosome consistent with the $5^{\prime}$ to $3^{\prime}$ direction of ribosome scanning, and we hypothesized that the ribosome occupying codon 11 may sterically hinder the recognition of the translation initiation codon by the next ribosome upstream, given the 20- to 30 nucleotide footprint of a ribosome (35) and the 32- to 39nucleotide interval between consecutive ribosomes in tightly packed polysomes (36). Local translation efficiency depends on the abundance of aminoacyl-tRNAs with compatible anticodons, and this is positively correlated with the relative usage of synonymous codons (37). It is conceivable that the effect of the codon substitution on translation efficiency might be felt only in female cells. Differences in codon usage bias have been described between male-, female-, and non-sex-biased genes in insects (38), avians (39), and fish (40), possibly arising from a selective advantage linked to the translation efficiency in either sex. Whether the sex dependency observed in the TLR7

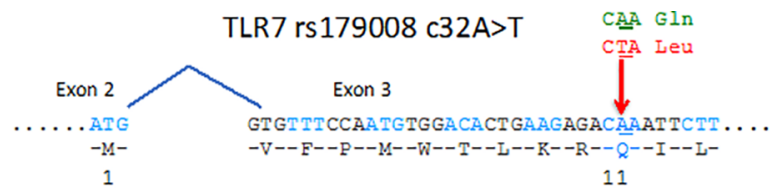

\section{Acute HIV infection}

- no effect on HIV-1 acquisition (26)

- $T / T$ allele => 10-fold reduction in HIV-1 viral load during acute HIV-1 infection (26)

- reduced IP-10 plasma levels and asymptomatic presentation in T carriers (26)

- blunted IFN $\alpha$ production by TLR7-stimulated pDCs in T allele carriers (A/T or $T / T)(26)$

- blunted TLR7 protein expression in T allele carriers (A/T or $\mathrm{T} / \mathrm{T})(26)$

- no effect on HIV-1 acquisition (34)

- no phenotype on TLR7 expression and pDC activation $(\mathrm{T} 0=\mathrm{A} 0)(26)$

- unknown effects on clinical parameters of HIV-1 acute infection??

\section{Chronic HIV infection}

\author{
Unknown??
}

- higher viral loads at set point (100 days to 2 years post-seroconvertion in therapynaive infected men

- and accelerated disease progression to advanced immune suppression (34)

FIGURE 1 | Impact of the sex-specific PQTL rs179008 c.32AVT SNP on TLR7-driven responses and parameters of HIV-1 infection in women and men. The rs179008 SNP is located in the leader sequence of TLR7 at position 32 in codon 11, and introduces an amino acid substitution from Gln to Leu. As shown in ref (26), the minor allele rs 179008 T of TLR7 impairs type I interferon production by pDCs in response to TLR7 ligands, but only in women. The sex bias in pDC function mirrors a genotype-dependent drop in TLR7 protein expression in female leukocytes, consistent with the notion that TLR7 dosage in pDCs determines type I interferon secretion. Primary HIV-1 infected women carrying the rs179008 T allele exhibited an almost 10-fold reduction in the RNA viral load, as well as reduction in cell-associated DNA, plasma IP-10, and symptomatic presentation at diagnosis (26). In ref (34), it was initially reported that men carrying the T alleles exhibited higher viral loads at set points compared to A0 men and showed accelerated reduction in CD4 ${ }^{+} \mathrm{T}$ cell counts (see Box 1). The allelic frequency of rs179008 in the European 1000 Genome project population is $0.76(\mathrm{~A})$ and $0.23(\mathrm{~T})$. The genotype frequencies found in our cohorts in average were: Female AA (62\%), AT (33\%), ТT (5\%), Male AO (73\%), TO (27\%). 
quantitative protein phenotype for rs179008 could be mediated by sex-differences in the regulatory mechanism of translation will deserve further investigations.

\section{Impact of Toll-Like Receptor 7 rs179008 Protein Expression Quantitative Trait Locus in Primary Human Immunodeficiency Virus 1 Infection in Women}

Because the $\mathrm{T}$ allele of rs179008 pQTL affects TLR7 protein expression and in turn TLR7-driven production of type I IFNs by pDCs in women, but not in men, its direct contribution on the clinical parameters of HIV-1 infection at the initial/acute phase of the disease was investigated in women (Figure 1). Contrary to the study of Oh and coll (34), a meta-analytical combination of two separate case-control settings, restricted to Caucasian women, did not support a significant genetic association of rs179008 with HIV-1 acquisition through the sexual route in women (26). In a striking contrast, in HIV-1 primary infected women from the French ANRS PRIMO cohort, the carriage of the rs179008 T allele was associated in the initial/acute phase of the disease with a decrease in viremia, a reduction in HIV-1 DNA associated cells, and lower plasma concentrations of the interferon alpha/gammainduced protein 10, IP-10 also known as CXCL10 (Figure 1). Symptomatic presentations of acute HIV-1 infection were also less common in T/T homozygous women, where the RNA viral load is decreased by an average of eight to nine times (26). Patients with detectable plasma IFN- $\alpha$ exhibit elevated levels of IP-10, and plasma IP-10 can be used as a surrogate of the IFN-I signature to demonstrate a positive correlation between IFN-I with viral load (41-43), and with a rapid disease onset during primary HIV-1 infection $(43,44)$. Thus, the higher frequency of asymptomatic clinical presentations at diagnosis for the T/T homozygous women implies a trend for a delayed onset of the symptoms of acute infection in this subgroup (26). Others frequent TLR7 SNPs were also investigated, such as the frequent intronic tag SNP, rs179012, previously associated with HIV-1 set-point viral load, especially in females (45), and a frequent functional SNP in the $3^{\prime}$ UTR of TLR7, rs3853839 in genetic association with the risk of developing systemic lupus erythematosus in males (46). None of these SNPs alone were found to be associated with the clinical parameters of a primary HIV-1 infection. Together, the genetic association studies reinforced the conclusion that rs179008 was a functional polymorphism of TLR7 in its own right (26), and strongly suggested that effector functions associated with TLR7 activation might exert dominant deleterious effects on viral load during acute HIV-1 infection in women (Figure 1).

\section{Evidence for a Negative Impact of the Toll-Like Receptor 7-Driven Innate Immunity and Type I Interferons Production During Natural Human Immunodeficiency Virus/Simian Immunodeficiency Virus Infection}

HIV-1/SIV transmission primarily occurs in the female reproductive tract (FRT) in a small founder population of cells at mucosal sites followed by a period of intense replication (47)
(Figure 2). The local expansion is fueled by the influx of new target cells recruitment, including $\mathrm{CD}^{+}{ }^{+} \mathrm{T}$ cells, through a gradient of chemokines produced by innate immune cells such as pDCs (20) and monocytes (48). These sequential events in early mucosal responses lead to $\mathrm{CD}^{+} \mathrm{T}$ cell recruitment (Figure 2). This starts with the release of chemokines, such as CCL20, by the epithelial mucosa sensitized by SIV, followed by a massive recruitment of $\mathrm{CCR}^{+}$pDCs which becomes shortly activated to produce IFN-I, IP-10/CXCL10 and other CCR $5^{+} \mathrm{T}$ cell-attracting chemokines (20) (Figure 2). The virus expands locally using the influx of target cells and then disseminate via lymphatic drainage to genital draining lymph nodes where more viruses are quickly produced in the T cell areas (47). SIV then spread through the thoracic duct to the lymphatic tissues resulting in an intense viral replication, resulting in high levels of plasma viremia and systemic dissemination of virus to lymphoid organs $(47,49)$.

Sex differences in the acquisition rates of HIV-1 infection have been observed with a two-fold higher risk for women compared to men following a serodiscordant encounter (50). This differences in transmission are likely a consequence of a unique anomatological characteristic of the FRT as compared to penile or rectal surfaces (51). Indeed, this anatomic difference is a critical domain of sex differences relevant to HIV infection with the paradox that an activated mucosal immunity at the cervicovaginal mucosa lowers the barrier to HIV infection (51). This was confirmed in female macaques exposed with TLR7 or TLR9 agonist prior SIV infection, with the aim to trigger antiviral immunity, showing that an endosomal TLR engagement is effective to enhance infection and viremia (52). In favor of an immune quiescence model of protection, it was further reported that HIV-negative exposed sex workers exhibited a depressed mucosal immunity as compared to uninfected controls (53). Indeed, genital tract inflammation during early HIV-1 infection predicts an increased risk for HIV acquisition (54), and higher viral load at set point and $\mathrm{CD} 4^{+} \mathrm{T}$ cell depletion in women. Thus, as suggested by others $(19,20,47)$, infection through the FRT may depend on IFN-I signaling for $\mathrm{CD} 4{ }^{+} \mathrm{T}$ cell recruitment and virus propagation. By contrast, infection through the rectal mucosa, which contains many resident $\mathrm{CD} 4^{+} \mathrm{T}$ cells can be protected by the antiviral properties of IFN-I (19). Thus, depending on the sites of entry rectum versus FRT antiviral mediators such as IFN-I might be protective or deleterious, respectively (19).

\section{How Can Sex-Differences in the Toll-Like Receptor 7-Driven Innate Plasmacytoid Dendritic Cell Function Contribute to Sex-Bias in Human Immunodeficiency Virus Infection?}

Based on all these considerations, the author propose that an enhanced TLR7 protein expression in a subset of women (c.32A allele carriers), associated with an enhanced innate sensing of viral components through TLR7, characterized by a higher IFN-I production by female pDCs could contribute to promote HIV-1 mucosal transmission and/or replication in the female genital 


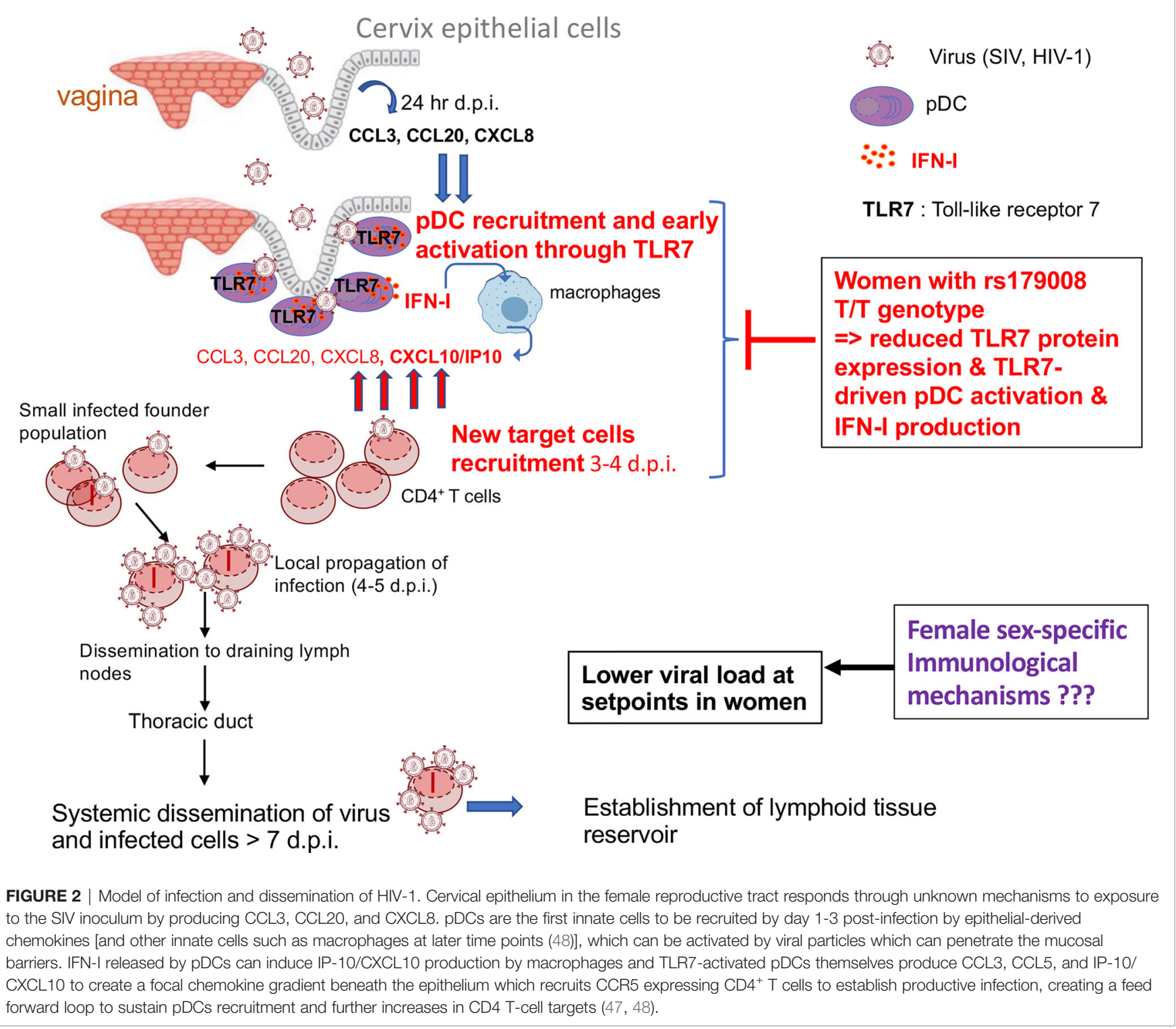

tract (Figure 2). This may explain the strong protective effect we observed in all clinical parameters of HIV-1 acute infection in women carrying the rs179008 T/T alleles, which reduces TLR7 protein expression in all immune cells and negatively impact the production of IFN- $\alpha$ by pDCs in response to HIV-1 ssRNA (26) (Figure 2). Thus, the higher functional responsiveness of woman pDCs appears deleterious in the general context of primary HIV-1 infection, suggesting that the better control of viral load and the HIV-1 reservoir in primary infected women compared to men is not due to the enhanced capacity of female pDCs to produce IFN-I during the early-stage of HIV-1 infection. This necessarily implies that the better control of viremia at setpoints in women is probably not a direct consequence of the anti-viral properties of IFN-I during the acute phase of infection as previously suggested (25) but could be due to a direct effect of estrogen-signaling on HIV-1 replication (55) or other unknown mechanisms (Figure 2).
By contrast, the detrimental role of IFN-I in chronic infection is supported by many studies and probably explains the faster progression to AIDS in women than in men. In chronic HIV infection, women have a higher level of $\mathrm{CD}^{+} \mathrm{T}$ cells activation after adjustment for viral loads, that correlates with an enhanced functional response of pDCs, suggesting that the sex-bias in the TLR7-driven production of IFN-I by pDCs could contribute to the inflammatory mechanism responsible for the more rapid disease progression seen in women (8). A deleterious role of pDC-derived IFN-I production has been illustrated by the lymphocytic choriomeningitis virus (LCMV) murine model of persistent viral infection. Here, blockade of IFN-I signaling even during the acute phase of infection facilitated a long-term viral clearance $(56,57)$. In humanized mouse and SIV models, pDCdepletion or IFN-I receptor (IFNAR) blockade, respectively, rescued human $\mathrm{T}$ cell depletion and function despite elevated 
BOX 1 | TLR7 rs179008 and HIV-1 Infection in Men.

In the study by Oh et al. (Figure 1), the TLR7 Gln11Leu polymorphism, however, was associated with a more severe HIV disease progression in HIV-1 infected men, while not tested in women (34). This study failed to confirm the functional impact of this SNP neither on the IFN-I production by pDCs from men, nor the TLR7 protein expression in male immune cells at a steady state (26). The impact of this SNP on primary acute infection in men will deserve further investigation. Although, in healthy donor cells, TLR7 protein expression was mostly found in pDCs, monocytes, and B cells, and it was also detected, at lower levels, in CD4 ${ }^{+} \mathrm{T}$ cells (63). In the latter subset, TLR7 engagement has been shown to induce human CD4 ${ }^{+}$T cell anergy and to promote T cell susceptibility to HIV-1 infection (63). Thus, the mechanism by which rs 179008 SNP of TLR7 regulates HIV-1 disease progression in men is currently unknown.

HIV-1 or SIV replication $(18,58)$. In these models, the upregulation of ISG, high level $\mathrm{T}$ cell activation, and $\mathrm{T}$ cell dysfunction persisted during antiretroviral therapy (ART), and blocking IFN-I signaling not only enhanced T cell recovery (59, $60)$ but also reduced the HIV-1 reservoir $(59,60)$, and delays HIV-1 rebound after ART discontinuation (59). Whether sex influences the therapeutic response to IFNAR blockade in chronic HIV will deserve further investigation.

\section{CONCLUDING REMARKS}

Although the results obtained with the rs179008 SNP might appear counter intuitive regarding previous works by others supporting a beneficial role of IFN-I-signaling and pDCs by controlling viral replication during acute infection in SIV and humanized mouse models $(18,19,61)$, they illustrate the "hard to predict" nature of manipulating IFN-I or innate immunity during the course of HIV-1/SIV infection (19, 20, 22, 47, 62). In women carrying the rs179008 $\mathrm{T}$ allele, although not totally inhibited, such early mechanisms initiated by pDCs-derived IFN-I would be less operating resulting in a significant inhibition of viral spreading and expansion at the early stage of infection (Figure 2). The consequences of this SNP at the later stage of infection and on chronic HIV-1 disease outcome appears protective in men (Box 1), through unknown mechanisms, and will, however, deserve further investigations in women (Figure 1). In light of the beneficial effect of IFN blockade on the HIV reservoir in humanized mouse models $(59,60)$, it has been proposed that targeting IFN-I signaling will reverse HIV/ ART-associated inflammatory diseases, rescue anti-HIV T cells,

\section{REFERENCES}

1. Scully EP. Sex Differences in HIV Infection: Mystique Versus Machismo. Pathog Immun (2018) 3(1):82-113. doi: 10.20411/pai.v3i1.238

2. Addo MM, Altfeld M. Sex-Based Differences in HIV Type 1 Pathogenesis. J Infect Dis (2014) 209(Suppl 3):S86-92. doi: 10.1093/infdis/jiu175

3. Sterling TR, Lyles CM, Vlahov D, Astemborski J, Margolick JB, Quinn TC. Sex Differences in Longitudinal Human Immunodeficiency Virus Type 1 RNA Levels Among Seroconverters. J Infect Dis (1999) 180(3):666-72. doi: 10.1086/314967

4. Sterling TR, Vlahov D, Astemborski J, Hoover DR, Margolick JB, Quinn TC. Initial Plasma HIV-1 RNA Levels and Progression to AIDS in Women and Men. N Engl J Med (2001) 344(10):720-5. doi: 10.1056/NEJM200103083441003

5. Gandhi M, Bacchetti P, Miotti P, Quinn TC, Veronese F, Greenblatt RM. Does Patient Sex Affect Human Immunodeficiency Virus Levels? Clin Infect Dis (2002) 35(3):313-22. doi: 10.1086/341249

6. Farzadegan H, Hoover DR, Astemborski J, Lyles CM, Margolick JB, Markham RB, et al. Sex Differences in HIV-1 Viral Load and Progression to AIDS. Lancet (1998) 352(9139):1510-4. doi: 10.1016/S0140-6736(98)02372-1 and reduce HIV reservoirs (22). IFNAR1-specific antibody is clinically safe and have been used in SLE patients which are preferentially women. Thus, taking into account the rs179008 SNP expression will be of particular interest, as one can speculate that women rs179008 $\mathrm{T}$ carriers would respond better to IFN-I blockade therapy than women expressing the frequent $\mathrm{A}$ allele only, in which TLR7 dosage and TLR7-driven pDC interferogenesis are at the highest. Together, it is therefore likely that the frequent rs179008 c.32.T pQTL of TLR7 might be beneficial in women at all stages of HIV infection.

\section{AUTHOR CONTRIBUTIONS}

The author confirms being the sole contributor of this work and has approved it for publication.

\section{FUNDING}

This work has been supported by grants from the French National Agency for Research on AIDS and Viral Hepatitis (ANRS, EP-53 study), SIDACTION, and Conseil Régional Occitanie-Midi-Pyrénées.

\section{ACKNOWLEDGMENTS}

The author wishes to thank his colleagues at INFINITY (Y Renaudineau, S Laffont, M Savignac and L Pelletier) for their critical readings of the manuscript.

7. Chang JJ, Woods M, Lindsay RJ, Doyle EH, Griesbeck M, Chan ES, et al Higher Expression of Several Interferon-Stimulated Genes in HIV-1-Infected Females After Adjusting for the Level of Viral Replication. J Infect Dis (2013) 208(5):830-8. doi: 10.1093/infdis/jit262

8. Meier A, Chang JJ, Chan ES, Pollard RB, Sidhu HK, Kulkarni S, et al. Sex Differences in the Toll-Like Receptor-Mediated Response of Plasmacytoid Dendritic Cells to HIV-1. Nat Med (2009) 15(8):955-9. doi: 10.1038/nm.2004

9. Klein SL, Flanagan KL. Sex Differences in Immune Responses. Nat Rev Immunol (2016) 16(10):626-38. doi: 10.1038/nri.2016.90

10. Laffont S, Seillet C, Guery J-C. Estrogen Receptor-Dependent Regulation of Dendritic Cell Development and Function. Front Immunol (2017) 8:108. doi: 10.3389/fimmu.2017.00108

11. Swiecki M, Colonna M. The Multifaceted Biology of Plasmacytoid Dendritic Cells. Nat Rev Immunol (2015) 15(8):471-85. doi: 10.1038/nri3865

12. Beignon AS, McKenna K, Skoberne M, Manches O, DaSilva I, Kavanagh DG, et al. Endocytosis of HIV-1 Activates Plasmacytoid Dendritic Cells via TollLike Receptor-Viral RNA Interactions. J Clin Invest (2005) 115(11):3265-75. doi: 10.1172/JCI26032 
13. Lepelley A, Louis S, Sourisseau M, Law HK, Pothlichet J, Schilte C, et al. Innate Sensing of HIV-Infected Cells. PloS Pathog (2011) 7(2):e1001284. doi: 10.1371/journal.ppat.1001284

14. von Sydow M, Sonnerborg A, Gaines H, Strannegard O. Interferon-Alpha and Tumor Necrosis Factor-Alpha in Serum of Patients in Various Stages of HIV1 Infection. AIDS Res Hum Retroviruses (1991) 7(4):375-80. doi: 10.1089/ aid.1991.7.375

15. Herbeuval JP, Nilsson J, Boasso A, Hardy AW, Kruhlak MJ, Anderson SA, et al. Differential Expression of IFN-Alpha and TRAIL/DR5 in Lymphoid Tissue of Progressor Versus Nonprogressor HIV-1-Infected Patients. Proc Natl Acad Sci USA (2006) 103(18):7000-5. doi: 10.1073/pnas.0600363103

16. Malleret B, Maneglier B, Karlsson I, Lebon P, Nascimbeni M, Perie L, et al. Primary Infection With Simian Immunodeficiency Virus: Plasmacytoid Dendritic Cell Homing to Lymph Nodes, Type I Interferon, and Immune Suppression. Blood (2008) 112(12):4598-608. doi: 10.1182/blood-2008-06162651

17. Bruel T, Dupuy S, Demoulins T, Rogez-Kreuz C, Dutrieux J, Corneau A, et al. Plasmacytoid Dendritic Cell Dynamics Tune Interferon-Alfa Production in SIV-Infected Cynomolgus Macaques. PloS Pathog (2014) 10(1):e1003915. doi: 10.1371/journal.ppat.1003915

18. Li G, Cheng M, Nunoya J, Cheng L, Guo H, Yu H, et al. Plasmacytoid Dendritic Cells Suppress HIV-1 Replication But Contribute to HIV-1 Induced Immunopathogenesis in Humanized Mice. PloS Pathog (2014) 10(7): e1004291. doi: 10.1371/journal.ppat.1004291

19. Sandler NG, Bosinger SE, Estes JD, Zhu RT, Tharp GK, Boritz E, et al. Type I Interferon Responses in Rhesus Macaques Prevent SIV Infection and Slow Disease Progression. Nature (2014) 511(7511):601-5. doi: 10.1038/nature13554

20. Li Q, Estes JD, Schlievert PM, Duan L, Brosnahan AJ, Southern PJ, et al. Glycerol Monolaurate Prevents Mucosal SIV Transmission. Nature (2009) 458(7241):1034-8. doi: 10.1038/nature07831

21. Deeks SG, Odorizzi PM, Sekaly RP. The Interferon Paradox: Can Inhibiting an Antiviral Mechanism Advance an HIV Cure? J Clin Invest (2017) 127(1):1035. doi: 10.1172/JCI91916

22. Su L. Pathogenic Role of Type I Interferons in HIV-Induced Immune Impairments in Humanized Mice. Curr HIV/AIDS Rep (2019) 16(3):224-9. doi: 10.1007/s11904-019-00444-7

23. Berghofer B, Frommer T, Haley G, Fink L, Bein G, Hackstein H. TLR7 Ligands Induce Higher IFN-Alpha Production in Females. J Immunol (2006) 177 (4):2088-96. doi: 10.4049/jimmunol.177.4.2088

24. Seillet C, Laffont S, Tremollieres F, Rouquie N, Ribot C, Arnal JF, et al. The TLRMediated Response of Plasmacytoid Dendritic Cells is Positively Regulated by Estradiol In Vivo Through Cell-Intrinsic Estrogen Receptor Alpha Signaling. Blood (2012) 119(2):454-64. doi: 10.1182/blood-2011-08-371831

25. Griesbeck M, Scully E, Altfeld M. Sex and Gender Differences in HIV-1 Infection. Clin Sci (Lond) (2016) 130(16):1435-51. doi: 10.1042/CS20160112

26. Azar P, Mejia JE, Cenac C, Shaiykova A, Youness A, Laffont S, et al. TLR7 Dosage Polymorphism Shapes Interferogenesis and HIV-1 Acute Viremia in Women. JCI Insight (2020) 5(12):e136047. doi: 10.1172/jci.insight.136047

27. Meditz AL, MaWhinney S, Allshouse A, Feser W, Markowitz M, Little S, et al. Sex, Race, and Geographic Region Influence Clinical Outcomes Following Primary HIV-1 Infection. J Infect Dis (2011) 203(4):442-51. doi: 10.1093/ infdis/jiq085

28. Cuzin L, Pugliese P, Saune K, Allavena C, Ghosn J, Cottalorda J, et al. Levels of Intracellular HIV-DNA in Patients With Suppressive Antiretroviral Therapy. AIDS (2015) 29(13):1665-71. doi: 10.1097/QAD.0000000000000723

29. Fourati S, Flandre P, Calin R, Carcelain G, Soulie C, Lambert-Niclot S, et al. Factors Associated With a Low HIV Reservoir in Patients With Prolonged Suppressive Antiretroviral Therapy. J Antimicrob Chemother (2014) 69 (3):753-6. doi: $10.1093 / \mathrm{jac} / \mathrm{dkt} 428$

30. Griesbeck M, Ziegler S, Laffont S, Smith N, Chauveau L, Tomezsko P, et al. Sex Differences in Plasmacytoid Dendritic Cell Levels of IRF5 Drive Higher IFNAlpha Production in Women. J Immunol (2015) 195(11):5327-36. doi: 10.4049/jimmunol.1501684

31. Laffont S, Rouquie N, Azar P, Seillet C, Plumas J, Aspord C, et al. XChromosome Complement and Estrogen Receptor Signaling Independently Contribute to the Enhanced TLR7-Mediated IFN-Alpha Production of Plasmacytoid Dendritic Cells From Women. J Immunol (2014) 193 (11):5444-52. doi: 10.4049/jimmunol.1303400
32. Souyris M, Cenac C, Azar P, Daviaud D, Canivet A, Grunenwald S, et al. TLR7 Escapes X Chromosome Inactivation in Immune Cells. Sci Immunol (2018) 3 (19):eaap8855. doi: 10.1126/sciimmunol.aap8855

33. Hagen SH, Henseling F, Hennesen J, Savel H, Delahaye S, Richert L, et al. Heterogeneous Escape From X Chromosome Inactivation Results in Sex Differences in Type I IFN Responses at the Single Human pDC Level. Cell Rep (2020) 33(10):108485. doi: 10.1016/j.celrep.2020.108485

34. Oh DY, Baumann K, Hamouda O, Eckert JK, Neumann K, Kucherer C, et al. A Frequent Functional Toll-Like Receptor 7 Polymorphism Is Associated With Accelerated HIV-1 Disease Progression. AIDS (2009) 23(3):297-307. doi: 10.1097/QAD.0b013e32831fb540

35. Lareau LF, Hite DH, Hogan GJ, Brown PO. Distinct Stages of the Translation Elongation Cycle Revealed by Sequencing Ribosome-Protected mRNA Fragments. Elife (2014) 3:e01257. doi: 10.7554/eLife.01257

36. Myasnikov AG, Afonina ZA, Menetret JF, Shirokov VA, Spirin AS, Klaholz BP. The Molecular Structure of the Left-Handed Supra-Molecular Helix of Eukaryotic Polyribosomes. Nat Commun (2014) 5:5294. doi: 10.1038/ ncomms 6294

37. Novoa EM, Ribas de Pouplana L. Speeding With Control: Codon Usage, tRNAs, and Ribosomes. Trends Genet (2012) 28(11):574-81. doi: 10.1016/ j.tig.2012.07.006

38. Hambuch TM, Parsch J. Patterns of Synonymous Codon Usage in Drosophila Melanogaster Genes With Sex-Biased Expression. Genetics (2005) 170 (4):1691-700. doi: 10.1534/genetics.104.038109

39. Mank JE, Hultin-Rosenberg L, Webster MT, Ellegren H. The Unique Genomic Properties of Sex-Biased Genes: Insights From Avian Microarray Data. BMC Genomics (2008) 9:148. doi: 10.1186/1471-2164-9-148

40. Yang L, Zhang Z, He S. Both Male-Biased and Female-Biased Genes Evolve Faster in Fish Genomes. Genome Biol Evol (2016) 8(11):3433-45. doi: 10.1093/gbe/evw239

41. Keating SM, Golub ET, Nowicki M, Young M, Anastos K, Crystal H, et al. The Effect of HIV Infection and HAART on Inflammatory Biomarkers in a Population-Based Cohort of Women. AIDS (2011) 25(15):1823-32. doi: 10.1097/QAD.0b013e3283489d1f

42. Roberts L, Passmore JA, Williamson C, Little F, Bebell LM, Mlisana K, et al. Plasma Cytokine Levels During Acute HIV-1 Infection Predict HIV Disease Progression. AIDS (2010) 24(6):819-31. doi: 10.1097/QAD.0b013e3283367836

43. Liovat AS, Rey-Cuille MA, Lecuroux C, Jacquelin B, Girault I, Petitjean G, et al. Acute Plasma Biomarkers of T Cell Activation Set-Point Levels and of Disease Progression in HIV-1 Infection. PloS One (2012) 7(10):e46143. doi: 10.1371/journal.pone.0046143

44. Ploquin MJ, Madec Y, Casrouge A, Huot N, Passaes C, Lecuroux C, et al. Elevated Basal Pre-Infection CXCL10 in Plasma and in the Small Intestine After Infection Are Associated With More Rapid HIV/SIV Disease Onset. PloS Pathog (2016) 12(8):e1005774. doi: 10.1371/journal.ppat.1005774

45. Mackelprang RD, Bigham AW, Celum C, de Bruyn G, Beima-Sofie K, JohnStewart G, et al. Toll-Like Receptor Polymorphism Associations With HIV-1 Outcomes Among Sub-Saharan Africans. J Infect Dis (2014) 209(10):1623-7. doi: 10.1093/infdis/jit807

46. Deng Y, Zhao J, Sakurai D, Kaufman KM, Edberg JC, Kimberly RP, et al. MicroRNA-3148 Modulates Allelic Expression of Toll-Like Receptor 7 Variant Associated With Systemic Lupus Erythematosus. PloS Genet (2013) 9(2):e1003336. doi: 10.1371/journal.pgen.1003336

47. Haase AT. Early Events in Sexual Transmission of HIV and SIV and Opportunities for Interventions. Annu Rev Med (2011) 62:127-39. doi: 10.1146/annurev-med-080709-124959

48. Shang L, Duan L, Perkey KE, Wietgrefe S, Zupancic M, Smith AJ, et al. Epithelium-Innate Immune Cell Axis in Mucosal Responses to SIV. Mucosal Immunol (2017) 10(2):508-19. doi: 10.1038/mi.2016.62

49. Moir S, Chun TW, Fauci AS. Pathogenic Mechanisms of HIV Disease. Annu Rev Pathol (2011) 6:223-48. doi: 10.1146/annurev-pathol-011110-130254

50. Patel P, Borkowf CB, Brooks JT, Lasry A, Lansky A, Mermin J. Estimating PerAct HIV Transmission Risk: A Systematic Review. AIDS (2014) 28(10):150919. doi: $10.1097 / \mathrm{QAD} .0000000000000298$

51. Scully EP. Sex Differences in HIV Infection. Curr HIV/AIDS Rep (2018) 15 (2):136-46. doi: 10.1007/s11904-018-0383-2

52. Wang Y, Abel K, Lantz K, Krieg AM, McChesney MB, Miller CJ. The TollLike Receptor 7 (TLR7) Agonist, Imiquimod, and the TLR9 Agonist, CpG 
ODN, Induce Antiviral Cytokines and Chemokines But do Not Prevent Vaginal Transmission of Simian Immunodeficiency Virus When Applied Intravaginally to Rhesus Macaques. J Virol (2005) 79(22):14355-70. doi: 10.1128/JVI.79.22.14355-14370.2005

53. Lajoie J, Juno J, Burgener A, Rahman S, Mogk K, Wachihi C, et al. A Distinct Cytokine and Chemokine Profile at the Genital Mucosa is Associated With HIV-1 Protection Among HIV-Exposed Seronegative Commercial Sex Workers. Mucosal Immunol (2012) 5(3):277-87. doi: 10.1038/mi.2012.7

54. Naranbhai V, Abdool Karim SS, Altfeld M, Samsunder N, Durgiah R, Sibeko $\mathrm{S}$, et al. Innate Immune Activation Enhances HIV Acquisition in Women, Diminishing the Effectiveness of Tenofovir Microbicide Gel. J Infect Dis (2012) 206(7):993-1001. doi: 10.1093/infdis/jis465

55. Das B, Dobrowolski C, Luttge B, Valadkhan S, Chomont N, Johnston R, et al. Estrogen Receptor-1 Is a Key Regulator of HIV-1 Latency That Imparts Gender-Specific Restrictions on the Latent Reservoir. Proc Natl Acad Sci USA (2018) 115(33):E7795-804. doi: 10.1073/pnas.1803468115

56. Teijaro JR, Ng C, Lee AM, Sullivan BM, Sheehan KC, Welch M, et al. Persistent LCMV Infection Is Controlled by Blockade of Type I Interferon Signaling. Science (2013) 340(6129):207-11. doi: 10.1126/science.1235214

57. Wilson EB, Yamada DH, Elsaesser H, Herskovitz J, Deng J, Cheng G, et al. Blockade of Chronic Type I Interferon Signaling to Control Persistent LCMV Infection. Science (2013) 340(6129):202-7. doi: 10.1126/science.1235208

58. Cheng L, Yu H, Li G, Li F, Ma J, Li J, et al. Type I Interferons Suppress Viral Replication But Contribute to T Cell Depletion and Dysfunction During Chronic HIV-1 Infection. JCI Insight (2017) 2(12):e94366. doi: 10.1172/ jci.insight.94366

59. Cheng L, Ma JP, Li JY, Li D, Li GM, Li F, et al. Blocking Type I Interferon Signaling Enhances T Cell Recovery and Reduces HIV-1 Reservoirs. J Clin Invest (2017) 127(1):269-79. doi: 10.1172/Jci90745
60. Zhen A, Rezek V, Youn C, Lam B, Chang N, Rick J, et al. Targeting Type I Interferon-Mediated Activation Restores Immune Function in Chronic HIV Infection. J Clin Invest (2017) 127(1):260-8. doi: 10.1172/Jci89488

61. Pham TNQ, Meziane O, Miah MA, Volodina O, Colas C, Beland K, et al. Flt3L-Mediated Expansion of Plasmacytoid Dendritic Cells Suppresses HIV Infection in Humanized Mice. Cell Rep (2019) 29(9):2770-82.e5. doi: 10.1016/ j.celrep.2019.10.094

62. Telenti A. HIV: The Mixed Blessing of Interferon. Nature (2014) 511 (7511):537-8. doi: 10.1038/nature13517

63. Dominguez-Villar M, Gautron AS, de Marcken M, Keller MJ, Hafler DA. TLR7 Induces Anergy in Human CD4(+) T Cells. Nat Immunol (2015) 16 (1):118-28. doi: 10.1038/ni.3036

Conflict of Interest: The author declares that the research was conducted in the absence of any commercial or financial relationships that could be construed as a potential conflict of interest.

Publisher's Note: All claims expressed in this article are solely those of the authors and do not necessarily represent those of their affiliated organizations, or those of the publisher, the editors and the reviewers. Any product that may be evaluated in this article, or claim that may be made by its manufacturer, is not guaranteed or endorsed by the publisher.

Copyright (C) 2021 Guéry. This is an open-access article distributed under the terms of the Creative Commons Attribution License (CC BY). The use, distribution or reproduction in other forums is permitted, provided the original author(s) and the copyright owner(s) are credited and that the original publication in this journal is cited, in accordance with accepted academic practice. No use, distribution or reproduction is permitted which does not comply with these terms. 